\title{
Inclusive Education: Education and Development of Persons with Disabilities in the Buea Municipality, Fako Division, South West Region of Cameroon
}

\author{
Bruno Bongwong Ph.D* \\ University of Bamenda, Faculty of Education, Department of Teacher Education, Bambili, NW Region,
} Cameroon

*Corresponding Author: Bruno Bongwong, University of Bamenda, Faculty of Education, Department of Teacher Education, Bambili, NW Region, Cameroon

\begin{abstract}
The study was investigated the influence of inclusive education on the education and development of persons with disabilities in the Buea Municipality of FakoDivison. The study was largely descriptive and adopted the survey research design. The sample population for the study consisted of thirty teachers, selected from three secondary schools in the Buea Municipality. Respondents were selected using the simple random sampling technique. The instrument used for data collection was a questionnaire for teachers. Data was analysed by calculating frequencies, percentages and the multiple response set and findings were displayed on tables. The findings revealed that non-discriminatory attitudes foster the education and development of persons with disabilities. Similarly, real-world experience in inclusive schools affects positively the education and development of persons with disabilities. Finally teacher training positively affect the education and development of persons with disability in Buea Municipality. It is recommended that short term programmes should be organised by pedagogic inspectors and school administrators to train teachers and students on appropriate inclusive practices. Also teacher training colleges should include in their curriculum in all departments extensive inclusive education training to enhance future teachers with skills and techniques on handling inclusive education.
\end{abstract}

Keywords: Inclusion, non-discrimination, real-world experience, teacher training

\section{INTRODUCTION}

The human sensation of social acceptance from the beginning of his life is affected by proper interactions with people surrounding him within his environment. The child during his growth and process of shaping social behaviour is affected by the individuals whom he interacts with, the community where he lives, and the philosophy that controls the nature of his school and family. The vital purpose that special education is seeking to achieve is to reach with the individual with disability to the highest degree of independence and self-reliance, and also to be a contributing member in the body of his or her society, not to be a burden. That is because productive human is considered a real wealth of any society. The individuals with disabilities in the community form more than $10 \%$ of the population. Therefore, governments officials and Non-GovernmentalOrganizations have direct attention toward persons with disability and provide them with all forms of educational services in regular schools in order to include those individuals into the surrounding environment in a way that affect them positively. And this helps them to adapt and to live comfortably in their society.

\subsection{Issues and Trends in the Development of Inclusive Education in Cameroon}

Inclusive education is a contentious term that lacks a tight conceptual focus, which may contribute to some misconception and confused practice. In relation to students with disability, the United Nations Educational, Scientific and Cultural Organisation (UNESCO, 1994) first stated that inclusive schools were the most effective way to counter discriminatory approaches and attitudes towards persons with disability. International legislation and policy subsequently evolved to challenge exclusionary practices and focus attention on equity and access to high-quality education for all, while respecting diversity (UNESCO, 2008). 
Inclusive Education: Education and Development of Persons with Disabilities in the Buea Municipality, Fako Division, South West Region of Cameroon

However, in trying to understand inclusive education, it is important to see how it has evolved over the years. Levin (1997) asserts that prior to the adoption of the inclusive school system, education for people with disabilities was mainly provided through special schools. The services were first initiated in order to cater for children who were blind and deaf, and such services were provided in residential schools. The genesis of special schools can be traced to Europe and North America during the eighteenth and twentieth centuries respectively. However, children with intellectual special needs were perceived to be uneducable; hence, drawing attention of professionals to look how these children can be educated with regular children.

The provision of Special Education Needs (SEN) to children with disabilities was seen as discriminatory (mainly by people with disabilities); hence, after World War II, people with disabilities started organizing and mobilizing themselves and began to advocate for the end of discrimination and inequalities in accessing social services (Noyoo, 2000). Many countries in the west started enacting social policies and legislations meant to eliminate all forms of barriers to participation in various life activities- and to better the living conditions of people (Noyoo, 2000). Therefore, the twentieth century marked the new dawn on the rights perspective, social participation and a new disability perspective (Levin, 1994). It was during this time that the term "inclusion"began to be used. The term referred to a dynamic process of people's participation withintheir social networks, regardless of their abilities.

While inclusion of people with disabilities in social activities is slowly making headway, because of limited resources, caution is called for when planning so that the resources can beutilized in the most efficient and effective manner. It is important to state that having an inclusive society is dependent on how well social services are planned, prepared and supported. This involves qualified personnel (administrators), community involvement and support, and a political will from the government. In the area of education, Enabling Education Network (EENET) was created to promote the inclusion of the marginalized groups such as people with disabilities in ordinary schools. Most children with disabilities are not educated in the mainstream school system but rather in the parallel special schools system. This problem is thought to be more pronounced in developing countries. The exclusion of people with disabilities from education often leads to severe consequences in later life: many do not gain the necessary skills to enter the competitive labour market and thus get excluded from economic activities (Noyoo, 2000).

Despite the complexity of inclusive education, many countries have seen the importance of educating children together, regardless of their abilities. The inclusive education philosophy recognizes and appreciates that all humans have a right to social services regardless of their orientation. It accepts individuals as unique, recognizing that all have a right to develop their abilities/capabilities (Cameron $\&$ Valentine, 2001). It focuses on the need to foster people's participation and eliminating all forms of discrimination in society. The philosophy of inclusion is thus important in ensuring that people develop social skills needed for their daily living (Noyoo, 2000).

Inclusive schools are thus perceived to be vital in providing education to children with special needs and those without special needs, alike. Croft (2010) posits that getting children with disabilities into schools is one thing, but overcoming attitudes, bureaucratic, and economic barriers is another. Therefore, presence alone is not enough to guarantee participation in all activities: a conducive learning environment must be ensured, as it is a prerequisite to inclusive education. These days, there are unprecedented efforts by policy makers and implementers in trying to come up with acceptable social policies that promote the wellbeing of all children regardless of their abilities.

Although the concept of inclusive education has been promoted internationally for two decades, multiple barriers remain to the full participation of children with disabilities in education. Lack of information, combined with discriminatory attitudes towards persons with disabilities at all levels of society, contributes to the continued neglect of their right to education. This partly explains the minimal rate of progress that has been made towards the enrolment and participation in the education process of children with disabilities.

\subsection{Statement of the Problem}

Numerous changes have occurred in the past 20 years regarding the education of children with disabilities. In the past, students who were eligible for special education services were typically 
Inclusive Education: Education and Development of Persons with Disabilities in the Buea Municipality, Fako Division, South West Region of Cameroon

served outside the regular classrooms and sometimes in separate schools. Current educational inclusion models are designed to include all students, regardless of degree and type of disability, into regular education classrooms. Inclusion allows all children with disabilities to be educated to the greatest extent possible with children of the same age who are regarded as normal. Although inclusion has been adopted by many school systems, the question still remainsif there would be acceptance of the child with disability into the regular classroom by peers without disabilities, the teachers or if there exist a conducive learning environment to accommodate the learners with disability. It is as a result of this backdrop that the researcher had to research on the influence of inclusive education on the education and development of persons with disabilities.

\subsection{Objectives}

This study was guided by the following specific objectives;

1. To investigate the effects of non-discrimination on the education and development of persons with disabilities.

2. To examine the effects of real-world experience on the education and development of persons with disabilities.

3. To find out the effects of teacher training on the education and development of persons with disabilities.

\section{LITERATURE REVIEW}

\subsection{Effects of Inclusion on the Education and Development of Persons with Disabilities}

Since inclusion has been in place, there have been many benefits to the general education population brought about by the inclusion of special education students. Many of these benefits are not easily measured, but may be very important to the development of the student's view of the real word. All parties involved should note. "If we believe that our students must learn to live in a pluralistic society, then inclusion deserves the extra effort and energy required of us" (Farlow, 1996). Van Dyke, Stallings, \& Colley (1995) reiterated that students in an inclusive setting develop a new sense of understanding and respect for one another and for human differences as they interact and understand each other. Inclusion then helps students understand one another, which in turn helps to reduce bias.

When normal students are placed into a tutoring role to assist special needs students, a number of positive outcomes can occur. The normal students realize that their knowledge base is greater than they assumed, enhancing their self-confidence. They also realize that they can have a positive effect on another person, creating the sense that they are important and can contribute to the benefit of society (Federico, Harrold, \& Venn, 2000). This makes the both learners to realize their effort matter. In his article Farlow (1996) told about a 15 year old sophomore boy with Down syndrome named Carlos. He was included in all group activities within the class that he was mainstreamed into, and extra credit was given when all group members participated. Over time, students began communicating more with each other as they worked to help Carlos. The benefits to the class were dramatic in that they worked much more cooperatively (Farlow, 1996).

Behavioural problems associated with some special needs children can sometimes be improved by an inclusive setting. In his article, Farlow (1996) also cited the example of a student named Bonito who, like his brothers, seemed destined to join a gang. He imitated gang behaviour in dress. He was defiant of authority, swearing when he disagreed with assignments, and was disrespectful of female teachers. By including him into a college prep economics/government class, which did not include students in gangs, he was able to meet the goals set for his inclusion. These goals were: following directions, showing respect for women, using appropriate language, and participating in discussions with peers. His teachers were most impressed.

\subsection{Conceptualising Students with Disabilities}

Zigmond (2001) posed the question, "What happened to our commitment to empirically based strategies and data driven decision-making at all levels of the special education enterprise?" When preparing this review of literature, the researcher found little quantitative analysis on the effects of inclusion on the academic achievement of regular education students. Although there was not an 
abundance of information available on the effects of inclusion on the performance of special education students, there was considerably more than the information available for regular education student achievement. In this section of the review of literature, a description of the available quantitative research will be summarized. Rea, McLaughlin, and Walther-Thomas (2002) investigated the relationship between placement in inclusive and non-inclusive special education programs. The researchers also investigated the academic and behavioural outcomes for students with specific learning disabilities in the middle school setting. The results of the quantitative piece of the study indicated that the two programs differed significantly. Students served in the inclusive classrooms earned higher grades, achieved equal or greater scores on standardized tests, committed no more behaviour infractions, and had better school attendance than students in the non-inclusive program.

Henning and Mitchell (2002) explored the experience and attitudes of two teacher education graduate students at Pennsylvania State University. One of the students was in early childhood special education and the other in social studies education. The teachers were given a Likert scale test to measure their attitudes concerning working with children with disabilities in an inclusive setting. The test was given on two occasions; before and after receiving training on inclusive education. An independent t-test was calculated and the results revealed that the attitudes of the teachers in regards to working in an inclusive setting with special education students improved after exposure to inclusion preparation training. The input of teachers has been viewed as a valuable component when evaluating inclusion programs.

According to Cook, Tankersly, Cook \& Landrum (2000), although it has not been empirically demonstrated that positive teacher attitudes toward the concept of inclusion will improve outcomes for special education students, researchers continue to study teacher attitudes towards the special education students in inclusive settings. Wischnowksi, Salmon, and Eaton (2004), described the efforts of a school district in western New York to implement inclusive practices at the elementary and middle school levels. The researchers collected data over a two year period on student achievement, behaviour referrals, and student self-concept. In terms of student achievement, the researchers found comparisons difficult to make based on state mandated testing; but that students with disabilities were not any less successful in inclusive settings, than when taught in more restrictive environments.

\subsection{Regular Education Students}

The focus of most of the research to date has been on the students with disabilities and how an inclusive service delivery approach supports or advances their educational progress (Korenich\& Salisbury, 2006). There are few studies which provided information in regards to regular education students placed in the inclusive setting. Kavale and Forness (2000) analysed the history of the inclusive debate and cited conflicting conclusions from research centred on regular education teachers and regular education students. The two researchers cited several qualitative research reports that showed general education teachers having both negative and positive attitudes about working in inclusive settings with students with disabilities. The attitudes of regular students towards students with disabilities in the inclusive setting were also found to be inconsistent. Kavale and Forness (2000) reported that the attitude of regular students towards special education students in the inclusive setting was usually found to turn negative when the special education students demonstrated "atypical behaviour".

\subsection{Alternatives to inclusion}

Before the inclusion model came into play classrooms were segregated by ability. Students with normal attributes made up the regular education class. Students who possessed special needs or had disabilities were often placed into special education classrooms. Not all students with special needs, however, received the attention they deserved. Some schools had limited budgets for qualified staff or suffered with inadequate facilities. Often times the facilities were located in some part of the school that was not needed by regular students. The special need students seemed to get what was left over, and high value was not being assigned toward their education (Stussman, 1997). Regular education also went through segregation. Students were being tracked by their abilities. The idea was that material could be developed and delivered to a specific level of ability, and that each group would benefit by being placed into the level where they could achieve the most success. The problem with 
Inclusive Education: Education and Development of Persons with Disabilities in the Buea Municipality, Fako Division, South West Region of Cameroon

this system is that by its very nature it is discriminatory. Once a placement is made the student is labelled in such a way that others would view them primarily in the context of that placement. To help eliminate the stereotype, some schools adopted names for various classes that attempted to hide the level that distinguished them from the rest. In the United States, Public Law 94-142 attempted to level the playing field by requiring students with disabilities to be placed into the least restrictive environment (Cronis and Ellis, 2000).

Schools choose to view a least restrictive environment differently. Some believe that it is a mandate to implement full inclusion for all students. Other schools have interpreted the law to mean that inclusion of special needs students should take place only if the placement is a good fit (Zera and Seitsinger, 2000). Schools also choose inclusion for economic reasons; "It is easier to add a student to an inclusionary setting than it is to create an individualized program for a child with special needs. The leap has too often been to a service-provision design, often made at the local level and driven by local economics rather than student need" (Zara and Seitsinger, 2000)

\subsection{Special need Students' View of Inclusive Rducation}

For some students inclusion is welcomed with open arms. Stussman, (1997) explains how he was miserable in the segregated special education classes. The ill feelings came from the stereotype associated with the placement. He goes on to explain that until he was allowed to be mainstreamed in an inclusion classroom, his progress academically was stifled. After he was allowed into the regular education population at the fifth grade, his attitude toward school improved, he no longer ate lunch at a separate table, and his academic achievement in school soared. This man now has two college degrees and a lifestyle described to be very normal (Stussman, 1997).

Other students may feel intimidated by being included into a classroom that is more general education than special education. Special needs students report being more comfortable in an inclusive setting when the teacher takes the time to know them, doesn't humiliate them or put them on the spot, identifies with their struggles, and gives them positive reinforcement on a daily basis (Stanovich, 1999).

In another report the researcher examined how special needs students feel about being pulled out of the general education classroom to receive individual help in the resource room. The findings showed that students often felt embarrassed about leaving, and often they would fabricate stories to justify to their friends why they were leaving class. These same students indicated that they were often targets of ridicule and name calling when the general education teacher is not supportive of students who are mainstreamed (Saland, Laurel and Duhaney, 1999). This indicates that generally special need students view inclusion as accommodating and conducive.

\subsection{Regular Education Students View of Inclusive Education}

Research has shown a great number of positive outcomes for students without disabilities who have been placed into inclusive classrooms with students possessing disabilities. Fisher (1999) identifies seven categories of positive outcomes when students without disability are placed in special classrooms. The first talks about an increased responsiveness to the needs of other people. Without inclusion regular students would not come in routine contact with students possessing special needs, but they may view other groups with scepticism. The second positive outcome was the valuing of relationships with people who have disabilities. Without inclusion, opportunities for creating relationships with people possessing disabilities would be almost non-existent. The third opportunity discussed was the possibility for personal development.

Another positive outcome for regular education students is that research has shown that students did not believe that their participation in inclusive classrooms had caused them to miss out on other valuable educational experiences(Peltier, 1997). Students also reported that the inclusion experience gave them the ability to understand other people, and improve their self-concept because of their role in helping others, and it also helped students reduce their fear of people with unusual behaviour and appearance (Peltier, 1997).

Regular education students also have negative concerns about their being included with students possessing disabilities. Ferguson (1999) pointed out that a majority of students surveyed did not want 
Inclusive Education: Education and Development of Persons with Disabilities in the Buea Municipality, Fako Division, South West Region of Cameroon

to be in a class with students possessing disabilities. The majority of the students interviewed in the same survey indicated that severely handicapped children do not belong in regular education classrooms. This same study also revealed however, that students who had previously been involved as peer tutors now have more positive attitudes about inclusion (Ferguson, 1999). This may suggest that students fear what they do not understand. Another fear that regular education students possesses is that the children with disability, will require excessive school resources and teacher attention and, therefore, jeopardize their learning opportunities (Saland, 2000).

\subsection{Parents View of Inclusive Education}

Federico, Harold, and Venn (2000) pointed out that parent of a special needs student explained that tolerance and respect for one another, caught as much as taught by teacher example, were demonstrated by the students in various ways in inclusive classrooms. Also Federico, Harold, and Venn (2000) stated that a parent of a regular student, revealed early negative feelings that grew out of proportion and caused general discontent towards inclusion as the parent was worried that if his child's placement into an inclusion classroom was not successful, for any reason, his daughter would be stuck there the entire year. But, by the middle of the school year the father noted how pleased he was with his daughter's academic progress and explained how good the learning atmosphere was within the classroom (Federico, Harrold, and Venn, 2000).

Gallagher, Floyd, Stafford, Taber, Brozovic and Alberto (2000)stated thatparents responded with very positive perceptions on inclusive practices, reporting many academic, behavioural, and social outcomes that they attributed to their child being in the in an inclusive class. Regardless of whom you ask, inclusion is a positive experience if those involved believe in it and work hard to make it work. Conversely, when there is little support, whether in the form of funding, or ideology, it will likely fail. If you think you can, you probably can.

\section{RESEARCH METHODOLOGY}

The area of study was Buea Municipality of Fako Division of the South West Region of Cameroon. The survey design was employed in this study. The questionnairewas used to answer the research questions. The target population consisted of 180 teachers from Bilingual Grammar School (BGS)Molyko, Summerset Bilingual Comprehensive College (SUBICCOL)Molyko and Baptist High School (BHS) Buea.

Table1: Demographic distribution of sample

\begin{tabular}{|c|c|c|c|}
\hline \multicolumn{2}{|r|}{ Characteristic } & $\mathbf{n}$ & $\%$ \\
\hline \multirow[t]{3}{*}{ Sex } & Male & 16 & 53.3 \\
\hline & Female & 14 & 46.7 \\
\hline & Total & 30 & 100.0 \\
\hline \multirow{4}{*}{$\begin{array}{ll}\text { Years } & \text { of } \\
\text { experience }\end{array}$} & 5 years and below & 10 & 33.3 \\
\hline & $6-10$ & 13 & 43.3 \\
\hline & 11 years and above & 07 & 23.4 \\
\hline & Total & 30 & $\mathbf{1 0 0 . 0}$ \\
\hline \multirow{5}{*}{$\begin{array}{l}\text { Academic } \\
\text { qualification }\end{array}$} & Secondary School Teachers Grade I Diploma (DIPES I) & 04 & 13.3 \\
\hline & Bachelor's Degree & 16 & 53.4 \\
\hline & Secondary School Teachers Grade II Diploma (DIPES II) & 06 & 20.0 \\
\hline & Master's Degree & 04 & 13.3 \\
\hline & Total & 30 & 100 \\
\hline \multirow[t]{4}{*}{ School } & BGS Molyko & 15 & 50.0 \\
\hline & SUBICCOL & 05 & 16.7 \\
\hline & BHS Buea & 10 & 33.3 \\
\hline & Total & 30 & 100 \\
\hline
\end{tabular}

From table 1 above, the sample population consisted of 30 respondents selected from three schools in the Buea Municipality. Majority (50.0\%) respondents were selected from BGS Molyko, some (33.3\%) respondents were selected from BHS while few (16.7\%) were selected from SUBICCOL Molyko. Also the sample consisted of $53.3 \%$ males and $46.7 \%$ females. Again most (43.3\%) respondents had a teaching experience between 6 and 10 years, some (33.3\%) had a teaching experience of 5 years and below while some (23.4\%) respondents had a teaching experience of 11 
Inclusive Education: Education and Development of Persons with Disabilities in the Buea Municipality, Fako Division, South West Region of Cameroon

years and above. Moreover, respondents' academic qualification was as follows: some (13.3\%) had DIPES I; majority (53.4\%) had a Bachelor's degree; some (20.0\%) had a DIPES II while some $(13.3 \%)$ had a Master's degree.

The simple random sampling technique was used for firstly for the selection of the schools and secondly for the selection of the sample population from the respective schools. The study schools were selected by employing the simple random sampling technique where by the names of the secondary school were written on tags which identified elements of the population to be sampled and the tags were placed in a container where by a child was asked to shuffle and pick at random one at a time. The three secondary schools were drawn and included for the study. Similarly the lottery method was used to pick or select respondents for the study as recommended by Amin (2005).

The questionnaire was structured into sections based on the objectives of the study. It consisted of statements rated on a four point Likert scale (Strongly agreed $=4$, agreed $=3$, disagreed $=2$ and strongly disagreed $=1$ ). Data for the study was collected within two weeks. Data was analysed descriptively by calculating frequencies and percentages of each indicator on a theme and the multiple response set was calculated for all the indicators to draw conclusions on the research question to be answered. Ethical considerations were taken into considerations and the informed consent of respondents was sought.

\section{FINDINGS}

Research Question One: What are the effects of non-discrimination on the education and development of persons with disabilities?

Table2: The effects of non-discrimination on the education and development of persons with disabilities

\begin{tabular}{|l|l|l|l|l|}
\hline \multicolumn{1}{|c|}{ Perceptions on non-discriminatory attitudes } & \multicolumn{2}{c|}{ Agreed } & \multicolumn{2}{c|}{ Disagreed } \\
\cline { 2 - 5 } & $\mathbf{n}$ & $\mathbf{\%}$ & \multicolumn{1}{c|}{ n } & \% \\
\hline Teachers give equal attention to all their students & 23 & 76.7 & 7 & 23.3 \\
\hline Teachers secure special seats for students with disabilities & 19 & 63.3 & 11 & 36.7 \\
\hline Equal task is given to all students despite disabilities & 07 & 23.3 & 23 & 76.7 \\
\hline Both regular and impaired students are paired in group work & 27 & 90.0 & 03 & 10.0 \\
\hline Both regular students and students with disability sit together in class & 30 & 100 & 00 & 00.0 \\
\hline Multiple response set (MRS) & $\mathbf{1 0 6}$ & $\mathbf{7 0 . 7}$ & $\mathbf{4 4}$ & $\mathbf{2 9 . 3}$ \\
\hline
\end{tabular}

From table 2 above, majority (76.7\%) respondents agreed that teachers give equal attention to all their students while $23.3 \%$ disagreed. Also, majority (63.3\%) indicates that teachers secure special seats for students with disabilities while some (36.7\%) disagreed. Still, some (23.3\%) respondents agreed that equal task was given to all students despite disabilities while majority $(76.7 \%)$ disagreed. More over majority $(90.0 \%)$ agreed that both regular and impaired students were paired in group work while few (10.0\%) disagreed. Furthermore all (100\%) respondents agreed that both regular students and students with disability sit together in class. The multiple response set indicated that majority $(70.7 \%)$ respondents agreed that students with disability experience non-discriminatory attitude in inclusive schools while some (29.3\%) disagreed. This shows that regular schools practicing inclusion provide a positive attitude to welcome learners with disabilities in Buea Municipality.

Research Question Two: What are the effects of real-world experience on the education and development of persons with disabilities?

Table3: The effects of real-world experience on the education and development of persons with disabilities

\begin{tabular}{|l|l|l|l|l|}
\hline Perception on real-world experience & \multicolumn{2}{l|}{ Agreed } & \multicolumn{2}{l|}{ Disagreed } \\
\cline { 2 - 5 } & $\mathbf{n}$ & $\mathbf{\%}$ & $\mathbf{n}$ & $\mathbf{\%}$ \\
\hline There is practical work after lesson for all students & 25 & 83.3 & 05 & 16.7 \\
\hline All students participate during sporting activities & 05 & 16.7 & 25 & 83.3 \\
\hline $\begin{array}{l}\text { Students have equal opportunity to express themselves and ideas } \\
\text { when doing manual work. }\end{array}$ & 26 & 86.7 & 04 & 13.3 \\
\hline All students are exposed to the job market after schooling. & 28 & 93.3 & 02 & 6.7 \\
\hline Students with disability go for field work & 10 & 33.3 & 20 & 66.7 \\
\hline MRS & $\mathbf{9 4}$ & $\mathbf{6 2 . 7}$ & $\mathbf{5 6}$ & $\mathbf{3 7 . 3}$ \\
\hline
\end{tabular}

The table 3 above indicates that majority (83.3\%) respondents agreed that there is practical work after lesson for all students while few (16.7\%) disagreed. Again few (16.7\%) respondents agreed that all 
Inclusive Education: Education and Development of Persons with Disabilities in the Buea Municipality, Fako Division, South West Region of Cameroon

students participate during sporting activities while majority (83.3\%) disagreed. Also majority (86.7\%) agreed that students have equal opportunity to express themselves and ideas shared when doing manual work while few (13.3\%) disagreed. Equally majority (93.3\%) respondents agreed that all students were exposed to the job market after schooling while very few (06.7\%) disagreed. Still some $(33.3 \%)$ respondents agreed that all students with disability go for field work while majority $(66.7 \%)$ disagreed. Based on the multiple response set, majority $(62.7 \%)$ respondents agreed that inclusive education provide all learners with real-world experience while some (37.3\%) disagreed. The findings indicate that inclusive education practice provides both learners with disability and regular students with real-world experiences.

Research Question Three: How does teacher training affect the education and development of persons with disabilities?

Table4: The effect of teacher's training on the education and development of persons with disabilities

\begin{tabular}{|l|l|l|l|l|}
\hline Perception on teacher's training & \multicolumn{3}{|l|}{ Agreed } & \multicolumn{2}{|l|}{ Disagreed } \\
\cline { 2 - 5 } & $\mathbf{n}$ & $\boldsymbol{\%}$ & $\mathbf{n}$ & $\mathbf{\%}$ \\
\hline Teachers use different teaching methods in class since there are diverse learners in class. & 30 & 100 & 00 & 00.0 \\
\hline Teachers faced no difficulty working with children with disabilities & 08 & 26.7 & 22 & 73.3 \\
\hline Teachers ensure vertical and horizontal communication in class & 27 & 90.0 & 03 & 10.0 \\
\hline Teachers have knowledge of subject matter & 24 & 80.0 & 06 & 20.0 \\
\hline Teachers are flexible in meeting students diverse needs & 30 & 100 & 00 & 00.0 \\
\hline MRS & $\mathbf{1 1 9}$ & $\mathbf{7 9 . 3}$ & $\mathbf{3 1}$ & $\mathbf{2 0 . 7}$ \\
\hline
\end{tabular}

Table 4 above, indicate that all (100\%) respondents agreed that teachers use different teaching methods in class since there diverse learners in class. Also some (26.7\%) agreed that teachers face no difficulty working with children with disabilities while majority (73.3\%) disagreed. Again, majority (90.0\%) agreed that teachers ensure vertical and horizontal communication in class while few (10.0\%) disagreed. Still majority (80.0\%) agreed that teachers have knowledge of subject matter while some $(20.0 \%)$ disagreed. Furthermore all $(100 \%)$ respondents indicated that teachers are flexible in meeting student's diverse needs. The findings based on the multiple response set indicates that majority (79.3\%) respondents agreed that teachers' training have a significant positive effect on the education and development of persons' with disability.

\section{DISCUSSION OF FINDINGS}

\subsection{The Effects of Non-Discrimination on the Education And Development of Persons with Disabilities}

The findings indicated that majority respondents agreed that students with disability experience nondiscriminatory attitude in inclusive schools while some disagreed. This shows that regular schools practicing inclusion have positive effect on the education and development of students with disabilities in Buea Municipality. This is evident as both regular and students with disabilities sat together in class. Similarly, teachers gave equal attention and assistance to all learners, teachers secure comfortable seats for learners with disability and teachers equally assigned both regular students and special students to learn in groups. Similarly Kavale and Forness (2000) pointed out that inclusive practices promotes interdependence of learners with special needs and foster a positive attitude of regular learners towards learners with special needs as such improving on the education and development of persons with special needs.

\subsection{The Effects of Real-World Experience on the Education and Development of Persons with Disabilities}

The findings revealed that majority respondents agreed that inclusive education provide all learners with real-world experience while some disagreed. This shows that inclusive education practice provides both learners with disability and regular students with real-world experiences. This is evident as the learners get involved in sporting activities and also go for field trip. The findings express that real world experiences take some form of practical lessons after studies; students have opportunities to express themselves and idea and are exposed to the job market. Similarly, Saland, Laurel and Duhaney (1999) pointed out that inclusion provides the opportunity for learners with special needs to adapt easily and participate in solving problems they encounter within their learning environment. 
Also Gallagher, Floyd, Stafford, Taber, Brozovic and Alberto (2000) stated that parents indicated that many academic, behavioural, and social outcomes of their children with special needs changed positively and the children equally adapted positively as they were placed in inclusive schools.

\subsection{The Effects of Teacher Training on the Education and Development of Persons with Disabilities}

The findings based indicates that majority of respondents agreed that teacher training have a positive effect on the education and development of persons' with disability. This is evident as few respondents indicated that teachers face difficulty dealing with learners with disabilities, while a greater proportion of the respondents indicated teachers use different teaching methods in class since there are diverse learners in class, teachers ensure vertical and horizontal communication, and teachers are flexible and have knowledge of subject matter. Similarly, Cook, Tankersly, Cook \& Landrum (2000) indicated that a positive teacher attitude affects the education and development of persons with special needs. Equally, Henning and Mitchell (2002) revealed that the attitudes of the teachers in regards to working in an inclusive setting with special education students improved after exposure to inclusion preparation training. The input of teachers has been viewed as a valuable component when evaluating inclusion programs. Teachers' training is essential when dealing with inclusive education since teacher education on inclusive practices positively influence the education and development of learners with disability.

\section{CONCLuSion}

This study is has shown that in Buea Municipality non-discriminatory attitudes manifested in regular schools practising inclusion positively affects the education and development of learners with special needs. This indicates that learners with special needs and regular learners when accepted unconditionally positively learn and develop their full potentials. Similarly the findings indicated that learners with special needs together with regular learners are exposed to real-world experiences in the inclusive environment which enables both learners to acquire appropriate skills which are needed for them to adapt to the sociocultural community. Finally, teacher training on inclusive practices affects positively the education and development learners with special needs in an inclusive environment. It should be noted that teacher education is an essential ingredient to foster inclusive education practices as it enables the teachers to create a positive learning environment to accommodate all learners. Similarly proper teacher education provide the teachers with knowledge and skills to handle, select teaching materials, methods and prepare lessons that will take care of the diverse needs of all the learners in the inclusive school.

\section{RECOMMENDATIONS}

It is recommended that the various pedagogic inspectors in the ministry of secondary education of Cameroon should design short term training programs in schools on inclusive education practices such that teachers and students would be drilled on appropriate inclusive education behaviours and attitude as all schools are now including students with special needs in the regular schools. Secondly, inclusive education courses should be an integral part of teacher education in the various teacher training colleges in Cameroon where by basic skills and the use of assistive technology to help learners with special needs would be taught to student teachers.

\section{REFERENCES}

[1] Baglieri, S. \& Knopf, J. (2004).Normalizing differences in inclusive education. Journal of Learning Disabilities, 37, 525-529.

[2] Farlow, L. (1996). A quartet of success stories: How to make inclusion work. Educational Leadership, 53(5), 51-55.

[3] Federico, M., Harrold, B., \& Venn, J. (2000). Inclusion reaches beyond the classroom. Kappa Delta Pi, 36(4), 178-180.

[4] Federico, M., Harrold, B., \& Venn, J. (2000). Inclusion reaches beyond the classroom. Kappa Delta Pi, 36(4), 178-180.

[5] Ferguson, J. M. (1999). High school students' attitudes toward inclusion of handicapped students in the regular education classroom. The Educational Forum, 63(2), 173-179. 
Inclusive Education: Education and Development of Persons with Disabilities in the Buea Municipality, Fako Division, South West Region of Cameroon

[6] Fisher, D. (1999). According to their peers: Inclusion as high school students see it. Mental Retardation, 37 (6), 458-467.

[7] Gallagher, P.A., Floyd, J. H., Stafford, A. M., Taber, T.A., Brozovic, S.A., \& Alberto, P. A. (2000). Inclusion of students with moderate of severe disabilities in educational and community settings: Perspectives from parents and siblings. Education and Training in Mental Retardation and Developmental Disabilities, 35(2), 135-147.

[8] Henning, M. \& Mitchell, L. (2002).Preparing for inclusion.Child Study Journal 32(1), 19-29.

[9] in middle and secondary schools. American Secondary Education Journal, 33(1), 33- 50.

[10] Kavale, K. \&Forness, S. (2000). History, rhetoric and reality: Analysis of the inclusion debate. Remedial and Special Education, 2, 279-296.

[11] Kemp, C. \& Carter, M. (2006).The contribution of academic skills to the successful inclusion of children with disabilities. Journal of Development and Physical Disabilities, 18(2), 123-147.

[12] Korenich, R., \& Salisbury, C. (2006).Learning opportunities and performance outcomes in inclusive elementary classrooms. Retrieved September 2, 2009, from http://www.uic-cfdc.org/pdf/Inclusive Classrooms_10.pdf

[13] Maglieri, K. \&Zigmond, N. (2005). Co-Teaching in middle school classrooms under routine conditions: Does the instructional experience differ for students with disabilities in co-taught and solo-taught classes? Learning Disabilities Research\& Practice, 20(2), 79-85.

[14] Mastropieri, M., Scruggs, T., Graetz, J., Norland, J., Gardizi, W., \&McDuffie, K. (2005). Case studies in co-teaching in the content areas: Successes, failures, and challenges. Intervention in School and Clinic, 40(5), 260-270.

[15] Murawski, W. (2006). Student outcomes in co-taught secondary English classes: How can we improve? Reading \& Writing Quarterly, 22(3), 227-247.

[16] Peltier, G. L. (1997, Summer). The effect of inclusion on non-disabled children: A review of research. Contemporary Education 68(4), 234-238.

[17] Rea, P., McLaughlin, V. \& Walther-Thomas, C. (2002).Outcomes for students with learning disabilities in inclusive and pulloutprograms.Council for Exceptional Children, 68(2), 203-222.

[18] Salend, S. 1., \&Duhaney, L. G. (1999). The influence of inclusion on students with and without disabilities and their educators.Remedial and Special Education, 20(2), 114-127.

[19] Salend, S.J. (2000). Strategies and sources to evaluate the impact of inclusion programs on students. Intervention in School and Clinic, 35_(5), 264-270.

[20] Stanovich, P. J. (1999). Conversations about inclusion.Teaching Exceptional Children, 31 (6), 54-58.

[21] Stussman, B. (1997). Inclusion isn't all academic.The Education Digest, 62(7), 19-21.

[22] Van Dyke, R., Stallings, M., \& Colley, K. (1995).How to build an inclusive school community. Phi Delta Kappan, 76(6), 475-479.

[23] Villa, R. A., Thousand, J. S., Nevin, A., \& Liston, A. (2005). Successful inclusive practices

[24] Wischnowski, M., Salmon, S., \& Eaton, K. (2004). Evaluating co-teaching as a means for successful inclusion of students with disabilities in a rural district. Rural Special Education Quarterly, 23(3), 3-14.

[25] Zera, D. A., \&Seitsinger, R.M. (2000). The oppression of inclusion. Educational Horizons, 79 (1), 16-18.

[26] Zigmond, N. (2001). Special education at a crossroads. Preventing School Failure, 45 (2), 70-74.

\section{AUTHORS' BIOGRAPHY}

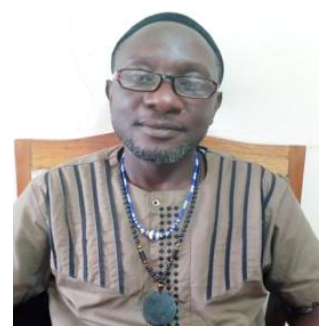

Bongwong Bruno, has a PhD in Indigenous/Applied Cognitive Psychology, a Master's Degree in Educational Psychology, Post Graduate Diploma in Educational Administration and a Bachelor's Degree in Philosophy. Dr. Bongwong Bruno is a Certified Forensic Investigative Professional (CFIP). He is an Afri-Cognitive Psychologist and Senior Lecturer in the Department of Educational Psychology, Faculty of Education, University of Buea. He currently serves as Head of Department for Teacher Education in the Faculty of Education, University of Bamenda, North West Region of Cameroon. He Previously Served as Music and Philosophy Teacher in the American School of Douala (ASD) for nine (9) years. Presently serving as Music Director since June 1990 till date.

Dr. Bongwong Bruno's areas of research and teaching include, developmental psychology, education process and teacher education, cognitive developmental processes, learning competence in language 
Inclusive Education: Education and Development of Persons with Disabilities in the Buea Municipality, Fako Division, South West Region of Cameroon

use, teaching styles, teacher education and training. The domain of this expertise spans from nursery through to higher education. Other areas of interests and expertise are evaluation training and research in education development projects, girls and gender education, education policy related to teacher education, pedagogical related issues, quality education as related to pedagogy and assessing outcomes. Dr. Bongwong Bruno has published widely in the above mentioned areas. He is a Research Consultant and a flexible postgraduate mentor to several $\mathrm{PhD}$ and Masters Students.

Citation: Bruno Bongwong. "Inclusive Education: Education and Development of Persons with Disabilities in the Buea Municipality, Fako Division, South West Region of Cameroon". International Journal of Humanities Social Sciences and Education (IJHSSE), vol. 6, no.6, 2019, pp. 30-40. doi: http://dx.doi.org/ 10.20431/2349-0381.0606005.

Copyright: (C) 2019 Authors. This is an open-access article distributed under the terms of the Creative Commons Attribution License, which permits unrestricted use, distribution, and reproduction in any medium, provided the original author and source are credited. 